\title{
SorCS2 deletion leads to altered neuronal lysosome activity
}

\author{
Sérgio Almeida ${ }^{1 *}$, André M. Miranda ${ }^{2}$, Andrea E. Tóth ${ }^{1}$, Morten S. Nielsen ${ }^{1}$ and Tiago Gil Oliveira ${ }^{2}$ \\ ${ }^{1}$ Department of Biomedicine, Aarhus University, Aarhus, Denmark \\ ${ }^{2}$ Life and Health Sciences Research Institute (ICVS), School of Medicine, University of Minho, Braga, Portugal
*Corresponding author: Sérgio Almeida, Department of Biomedicine, Aarhus University, Høegh- Guldbergsgade 10, DK-8000C Aarhus, Denmark. Phone: +45 60511406. E-mail: sergio.almeida@biomed.au.dk

\section{Abstract}

Vps10p domain receptors are important for regulating intracellular protein sorting within the central nervous system and as such constitute risk factors for different brain pathologies. Here, we show that removal of SorCS2 leads to altered lysosomal activity in mouse primary neurons. SorCS2-/ neurons show elevated lysosomal markers such as LAMP1 and acidic hydrolases including cathepsin B and D. Despite increased levels, SorCS2 ${ }^{-/}$neurons fail to degrade cathepsin specific substrates in a live context. SorCS2deficient mice present an increase in lysolipids, which may contribute to membrane permeabilization and increased susceptibility to lysosomal stress. Our findings highlight SorCS2 as an important factor for a balanced neuronal lysosome milieu. 


\section{Introduction}

Proper sorting of proteins to specific compartments is crucial for regular cell function. Therefore, abnormal protein sorting has been pointed out as the underlying cause of many brain pathologies like Alzheimer's and Parkinson's disease (Wang, Chan et al. 2013). The vps10p domain (Vps10p-D) receptors are a group of five structurally related type 1 transmembrane proteins that includes sortilin, SorLA, SorCS1, SorCS2 and SorCS3. As a common feature, the family members act as sorting receptors for different proteins within the central (CNS) and peripheral nervous system (PNS) (Willnow, Petersen et al. 2008). Predictably, the receptors have been shown to constitute risk factors for different neurodegenerative diseases such as frontotemporal dementia (FTD) in the case of sortilin (Philtjens, Van Mossevelde et al. 2018) and Alzheimer's disease (AD) in the case of SorLA (Andersen, Reiche et al. 2005, Rogaeva, Meng et al. 2007). Sortilin, the archetype Vps10p-D receptor, has been pointed out as an endocytic and intracellular sorting receptor for the endo-lysosomal pathway in which it is responsible for the trafficking of different lysosomal proteins, such as acid sphingomyelinase (Ni and Morales 2006), cathepsins D and H (Canuel, Korkidakis et al. 2008) and progranulin (Hu, Padukkavidana et al. 2010). This lysosomal directed sorting is conveyed by the same sorting mechanism as observed with the mannose-6 phosphate receptors (M6PR), which are also responsible for delivery of newly synthesized hydrolases from the trans-Golgi network (TGN) to the late endocytic compartments (Nielsen, Madsen et al. 2001, Gary-Bobo, Nirdé et al. 2007, Mari, Bujny et al. 2008).

SorCS2 is a receptor of the same family, and belongs to the SorCS subfamily of receptors. It differs from sortilin by having a leucine rich domain and a Polycystic Kidney Disease (PKD) domain on the extracellular part (Hermey, Riedel et al. 1999) and is predominantly expressed in the CNS neurons, located mostly intracellularly, but it can also be found at the cell surface (Glerup, Olsen et al. 2014). SorCS2 has been associated with bipolar disorder (Baum, Akula et al. 2008, Ollila, Soronen et al. 2009), schizophrenia (Christoforou, McGhee et al. 2011) and attention deficit-hyperactivity disorder (ADHD) (Alemany, Ribasés et al. 2015) and different ligands have been identified such as neurotrophins for instance (Deinhardt, Kim et al. 2011, Anastasia, Deinhardt et al. 2013, Glerup, Olsen et al. 2014). Recently, SorCS2 has been implicated in different processes of the endocytic recycling pathway. By binding to cysteine transporter, excitatory amino acid transporter 3 (EAAT3), SorCS2 facilitates EEAT3 cell surface expression and enables neuronal oxidative stress defense (Malik, Szydlowska et al. 
1 2019). Loss of SorCS2 leads to reduced EAAT3 cell surface expression due to a shift of the receptor

2 from the recycling endosome to the late endosome bound for degradation. Additionally, SorCS2 was

3 found to interact with the key component of the retromer complex Vps35, promoting the trafficking of

$4 \quad$ NR2A subunit to the dendritic surface of medium spiny neurons (MSNs), showing that impaired SorCS2

5 activity contributes to motor coordination deficits in Huntington's disease (HD) (Ma, Yang et al. 2017).

6 Despite these recent advances, the effect of SorCS2 deficiency in late compartments of the endocytic

7 pathway remains unknown.

8

Here, we show that the absence of SorCS2 leads to inversed modulation of early and late endocytic compartments in primary mouse neurons and mouse brain cortex. Additionally, we show that SorCS2 genetic ablation in mouse primary neurons impairs lysosomal degradation of cathepsin B substrates and renders the neurons more susceptible to lysosomal related stressors such as chloroquine (CQ) and alpha-synuclein ( $\alpha$-syn). Finally, SorCS2-deficient mice display an increase in lysolipids that may account for altered lysosomal milieu and subsequent decreased lysosomal degradation. Taken together, these findings describe a novel role for SorCS2 as a regulator of lysosomal environment and function. 


\section{$1 \quad$ Results}

SorCS2 ablation leads to altered endo-lysosomal associated proteins in the mouse brain and

We started by evaluating the effects of SorCS2's absence on the different endo-lysosomal compartments in primary mouse neurons, such as Rab5 and EEA1 for early endosomes, Rab7 for late endosomes/multivesicular bodies and LAMP1 for lysosomes (Fig. 1A). Immunoblot analysis revealed higher levels of the early endosome marker Rab5, while the subsequent downstream compartment markers, EEA1 and Rab7, showed decreased levels in SorCS2 $2^{-/}$neurons. Interestingly, the levels of the lysosome associated marker LAMP1 were also found to be increased in SorCS2-deficient neurons. Immunocytochemistry of hippocampal primary WT and SorCS2 $2^{-/-}$neurons analyzed by high content screening microscopy and scanR showed elevated numbers of LAMP1 positive vesicles in each SorCS2/- neuron and decreased number of EEA1 positive vesicles. This is in accordance with the immunoblot results and further shows a greater abundance of lysosomes and decreased intermediate compartments in the absence of SorCS2 (Fig. 1B). Next, we investigated the impact of SorCS2's absence on the lysosomal hydrolases cathepsin B (CatB) and cathepsin D (CatD). CatD (and CatB) is produced in the biosynthetic pathway as precursor proCatD (46 kDA) and sorted to the endo-lysosomal compartment, where it is processed into a mature form (30 $\mathrm{kDa}$ ) at acidic $\mathrm{pH}$ (Braulke and Bonifacino 2009). We found elevated levels of CatB and D mature forms, which correlated with increased number of lysosomes in neurons. Notably, we were able to assess a higher maturation of CatD based on the CatD/proCatD (Fig. 2A). This cathepsin maturation seemingly points to proper lysosomal function.

With the purpose of assessing the lysosomal degradative capacity, WT and SorCS2 $2^{-/-}$neurons were processed to measure CatB activity ex vivo (Fig. 2B). As expected, the increased mature CatB present in SorCS2 $2^{-/}$neurons displayed increased signal when compared to WT neurons, as more enzymes will be able to degrade the substrate faster and produce higher signal. In addition, to evaluate CatB activity in vitro, we performed live imaging of primary neurons treated with Magic Red ${ }^{\mathrm{TM}}$ Cathepsin B, a membrane-permeable anionic compound that accumulates in acidic compartments and emits 
different time points $(30,60$ and $180 \mathrm{~min})$ revealed time-dependent increase in fluorescence in WT

2

neurons (Fig. 2C), suggesting increased load in late endocytic compartments. SorCS2 $2^{-/}$neurons failed to produce the fluorescent product. As such, our results suggest that, despite elevated lysosomal number and increased cathepsin levels, CatB shows decreased processing in vivo, indicating possible changes in the lysosomal milieu.

Immunoblot analysis of cortex tissue from WT and SorCS2 $2^{-/-}$adult mice further confirmed the observations in neurons regarding increased levels in lysosomal associated proteins (LAMP1, CatB and CatD mature forms) (Fig. 2D). Additionally, we performed ex vivo CatB activity assay in brain hippocampus from 1-year-old mice WT and SorCS2 $2^{-/}$. SorCS2 deletion in mice resulted in elevated CatB activity when compared to WT, although not statistically significant (Fig. 2E).

\section{SorCS2 $^{-/-}$neurons are more susceptible to lysosomal stress}

Since there is an increase in lysosomes upon SorCS2 ablation, we evaluated the neuronal response to lysosomal stressors, such as CQ and $\alpha$-syn. Cultured WT and SorCS2/-- primary mouse neurons were incubated with $50 \mu \mathrm{M}$ CQ, known for inhibiting lysosomal acidification and impair autophagy (Seglen, Grinde et al. 1979, Poole and Ohkuma 1981, Mizushima, Yoshimori et al. 2010) (Fig. 3A). SorCS2 $2^{-/-}$ neurons show higher levels of cleaved caspase-3 when compared to WT neurons, indicating a higher rate of apoptosis. Autophagy marker LC3 was probed as a control for lysosomal neutralization and indeed, LC3-II accumulates to the same extent upon treatment with CQ in both genotypes, suggesting that apoptosis was independent of autophagy machinery. Higher susceptibility was also confirmed using LIVE/DEAD ${ }^{\mathrm{TM}}$ Cytotoxicity assay in which SorCS2 $2^{-/-}$neurons show a higher percentage of dead cells when submitted to lysosomal stress (Fig. 3B).

It has been documented that lysosome biogenesis is elevated when cells are exposed to exogenous $\alpha$-syn, as this protein is mainly cleared by the endo-lysosomal pathway (Hoffmann, Minakaki et al. 2019). Therefore, to evaluate the lysosomal response to robust levels of $\alpha$-syn exposure in the absence of SorCS2, neurons were incubated with $14 \mu \mathrm{g} / \mathrm{ml}$ of monomeric $\alpha$-syn for $24 \mathrm{~h}$, and then stained with Lysosensor $^{\mathrm{TM}}$ Green DND-189, a pH sensitive probe (Fig. 3C). Neurons were subsequently analyzed using high content screening microscopy. We confirmed an increase in lysosomal numbers, as expressed 
1 by the number of punctate structures (Fig. 3D), but also higher acidification of vesicles when SorCS2 is

2 ablated, as expressed by increased fluorescence intensity (Fig. 3E). However, upon $\alpha$-syn treatment, while lysosomal numbers increased in WT neurons, KO neurons were unable to elevate their lysosomal numbers and showed decreased vesicle intensity compared to baseline. This loss in acidification might be due to lysosomal membrane permeabilization (LMP) and consequent leakage (Jiang, Gan et al. 2017).

\section{Removal of SorCS2 increases lysolipid production in mouse cortex}

To gain further insight into the potential effect of SorCS2 deletion in the endo-lysosomal compartments, we performed a mass spectrometry lipidomic analysis in the brain cortex of adult WT and SorCS2 $2^{--}$mice. We identified 19 lipid classes that were further divided into 147 lipid species (Fig. 4A). Of all the lipid classes, lysolipids lysophosphatidic acid (LPA) and lysophosphatidylserine (LPS) were the most significantly elevated. While these are of very reduced abundance $(0.02-0.05 \%$ of all lipids measured), lysolipids can be synthesized in late endocytic compartments and, given their physical structure, they can increase the instability of phospholipid membranes and consequently increase their permeabilization (Harayama and Riezman 2018). Lysolipids may act as intermediates for glycerophospholipid synthesis, but may also be produced by action of phospholipases, namely PLA, of which there are many isoforms differently localized (D'Arrigo and Servi 2010).

A significant reduction is also observed in phosphatidic acid (PA) and sphingomyelin (SM). To further amplify the study, individual lipid species were investigated (Fig. 4B). A significant impairment in 35 different lipid species was seen. Curiously, we find decreased sphingomyelin and ceramide species, while no changes were detected in more complex sphingolipids, suggesting decreased synthesis or increased degradation. Interestingly, the precursor for these species, sphingosine has been reported to induce LMP in increased concentrations (Kågedal, Zhao et al. 2001). Additionally, changes are observed in multiple phosphatidylcholine (PC) and phosphatidic acid (PA) species. 


\section{Discussion}

Lysosomes are central organelles crucial for proper cell function and lysosomal dysfunction has been implicated in many neurodegenerative diseases (Zhang, Sheng et al. 2009). Defects in trafficking of different proteins may result in importer sorting of different components which will cause changes in the different compartments of the endocytic pathway and ultimately impair the lysosome degradative capacity (Ghosh, Dahms et al. 2003). SorCS2, being a transmembrane sorting receptor, has been reported to act as a co-receptor and together with TrkB facilitate BDNF signaling and TrkB translocation to the postsynaptic densities (Glerup, Bolcho et al. 2016). Together with the recent discoveries of SorCS2's involvement in the endocytic recycling pathway and therefore controlling cell surface exposure of receptors (Ma, Yang et al. 2017, Malik, Szydlowska et al. 2019, Yang, Ma et al. 2021), it is expected that its absence will affect the different endocytic compartments.

Here, we show that the absence of SorCS2 leads to an increase in lysosomes and, even though cathepsins are shown to mature, their activity in live neurons is seemingly impaired, pointing towards changes in the lysosomal milieu such as altered $\mathrm{pH}$, altered trafficking of co-factors or accumulation of enzymatic inhibitors, which may be unfavorable to protease action. Indeed, despite increased lysosomal acidification, SorCS2-deficient neurons show an abnormal reaction when faced with lysosomal stressors such as CQ and $\alpha$-syn. SorCS2 ${ }^{-/}$neurons show a higher death rate in response to CQ, are unable to raise their lysosomes in response to exogenous $\alpha$-syn and present decreased lysosomal acidification. This may suggest that elevated levels of LAMP1 and lysosomal acidification at steady-state levels already indicate an underlying defect and upregulated response to attempt to establish homeostasis, which is unelastic in the context of additional stress. Importantly, exogenous exposure to $\alpha$-syn has been shown to induce lysosomal rupture following endocytosis in neuronal cell lines and induce a CatB dependent increase in reactive oxygen species (ROS) (Freeman, Cedillos et al. 2013, Jiang, Gan et al. 2017).

Lipidomic analysis report specific changes in lipid classes and species, suggesting a relative localized effect caused by the absence of SorCS2. The increase observed in lysolipids will affect phospholipid membranes by altering their shape and constitution, further supporting the vulnerability of the late endocytic compartments (Fuller and Rand 2001, Chevallier, Chamoun et al. 2008, Bissig and Gruenberg 2013). This might be mediated by phospholipases such as PLA2G4A/cPLA2, which has been shown to promote LMP and inhibition of autophagy flux leading to neuronal dysfunction and eventually 
cell death in mice with traumatic brain injury (Sarkar, Jones et al. 2020). In order to investigate the possible LMP, future studies should be conducted in WT and SorCS2/- neurons to directly image effectors of lysosomal membrane repair, such as early recruitment of galectin and subsequent autophagy machinery upon $\alpha$-syn incubation (Aits, Kricker et al. 2015). It will be interesting to address how lysosomal function is affected, whether there is decreased formation of engulfing autophagosomes or decreased processing of these structures. Notably, when incubated with CQ, SorCS2 $2^{-/-}$neurons reveal the same extent of LC3-II accumulation as control neurons. This suggest others aspects than autophagy are impaired, hence the impaired levels of specific endocytic modulators (e.g. Rab7 and Rab5).

SorC2 deficient mice display behavioral changes such as impaired formation of long-term memory, increased risk taking, ADHD-like behavior (Glerup, Olsen et al. 2014, Glerup, Bolcho et al. 2016, Olsen, Wellner et al. 2021) and social memory deficit (Yang, Ma et al. 2021). Curiously, some of these phenotypes have been reported in phospholipase D1 (PLD1) deficient mice, which also show decreased levels of the PA lipid (Santa-Marinha, Castanho et al. 2020) as our lipidomics results on $\mathrm{SorCS}^{-/-}$. PLD1 is a major source of PA and it is primarily associated with the endosomal system where it was suggested to be recruited by class III PI 3-kinase Vps34 (Dall'Armi, Hurtado-Lorenzo et al. 2010), which is a major regulator of endolysosomal and autophagic functions (Backer 2016). Finally, disruption of neuronal Vps34 function impairs autophagy, lysosomal degradation and lipid metabolism, affecting different cellular compartments and causing endolysosomal membrane damage (Miranda, Lasiecka et al. 2018) similar to what we observe in SorCS2 $2^{-/-}$neurons.

SorCS2 mediates recycling of different receptors to the cell surface, documented to rely on the binding to Vps35 (Ma, Yang et al. 2017). The component of the retromer complex Vps35 is a major regulator of endosomal sorting (Burd and Cullen 2014) and several studies have shown that reduced levels of Vps35 affect the traffic of cation-independent (CI)-M6PR (Arighi, Hartnell et al. 2004, Seaman 2004, Seaman 2007, Wassmer, Attar et al. 2007, Bulankina, Deggerich et al. 2009, Miura, Hasegawa et al. 2014, Hirst, Itzhak et al. 2018, Seaman 2018). Furthermore, loss of retromer Vps35 subunit impairs targeting and processing of M6PR-depedent hydrolases, causing ultrastructural alterations and compromised lysosomal function, leading to impaired autophagy (Cui, Carosi et al. 2019). Interestingly, phospholipase iPLA2-VIA (the fly homolog of PLA2G6) has been shown to bind to Vps35 and enhance retromer function to promote protein and lipid recycling, where loss of this phospholipase impairs 
1 retromer and lysosomal function in flies (Lin, Lee et al. 2018). Future experiments should address the

2 levels and localization of Vps35 and PLA2G6 under the absence of SorCS2.

3

In summary, we conclude that SorCS2 may act as an indirect mediator of neuronal lysosomal

4 function and a missing piece in the regulation and correct sorting of the retromer complex subunit Vps35.

5 In the absence of SorCS2, Vps35 is mistrafficked leading to abnormal phospholipase activity and further

6 irregular sorting of components to the lysosomes, compromising equilibrium. The consequent decrease

7 in acidic hydrolase activity altered the lysosomal milieu causing higher vulnerability to lysosomal

8 stressors. The data collectively suggests promising avenues for the investigation of the neuronal

9 endocytic pathway mechanisms regulated by SorCS2. 


\section{Materials and Methods}

\section{Reagents and antibodies}

3 Bafilomycin A1 (100 nM, Merck, B1793), CQ diphosphate (50 $\mu \mathrm{M}$, Merck, C6628), mouse monomeric

4 $\alpha$-synuclein (kind gift from Poul Henning Jensen, Aarhus University). Antibodies: $\alpha$-synuclein (BD Biosciences, 6107887, 1:1000 in WB), $\beta$-actin (Merck, A5441, 1:5000 in WB), Cathepsin B (Cell Signaling, D1C7Y, 1:1000 in WB), Cathepsin D (Abcam, ab75852, 1:1000 in WB), Cleaved Caspase-3 (Cell Signaling, 9661, 1:1000 in WB), EEA1 (Cell Signaling, C45B10, 1:1000 in WB and 1:100 in ICC) EGFR (EMD Millipore, 06-847, 1:1000 in WB and 1:100 in ICC), LAMP1 (Abcam, ab24170, 1:1000 in WB and 1:100 in ICC), LC3 (Novus Biologicals, NB600-1384, 1:1000 in WB), Rab5 (Synaptic Systems, 108011, 1:1000 in WB), Rab7 (Abcam, ab137029) and SorCS2 (R\&D systems, AF4237, 1:1000 in WB and $1: 100$ in ICC).

\section{Animals}

1 year-old female C57BL/6j and SorCS2 $2^{-/}$mice were used for experiments. SorCS2 $2^{-/-}$on a C57BL/6j background were described before (Glerup, Olsen et al. 2014). The mice were bred and housed at the Animal Facility at Aarhus University. The mice were housed in groups and kept under pathogen-free conditions with a $12 \mathrm{~h}$ light/ $12 \mathrm{~h}$ dark schedule with food and water ad libitum. All procedures involving mice were approved by the Danish Animal Experiment Inspectorate (license 2017-15-0201-01203) and complied with Danish and European regulations (directive 2010/63/EU) concerning experimentation and care of experimental animals.

\section{Cell culture}

Primary cortical and hippocampal neurons were obtained from wild-type and SorCS2 $2^{-/}$postnatal day 0 mouse pups of either sex (Glerup, Olsen et al. 2014). Pups were euthanized by decapitation, brains removed, and hippocampi or cortex dissected into ice-cold Leibowitz's L-15 medium (Life technologies, 11415049). Tissue was dissociated for 30-40 min using $20 \mathrm{U} / \mathrm{mL}$ pre-activated papain (Bionordica, WBT-LS003126) and washed in DMEM containing $0.01 \mathrm{mg} / \mathrm{mL}$ DNase I (Merck, DN25) and 10\% FBS 
1 before being triturated in the same buffer. Following trituration, DMEM was substituted with 2 Neurobasal-A Medium (Gibco, 10888022) supplemented with 2\% B-27 (Gibco, 17504044), 2 mM 3 GlutaMAX (Gibco, 35050), $100 \mu \mathrm{g} / \mathrm{mL}$ primocin (Invivogen, ant-pm-2), $20 \mu \mathrm{M}$ floxuridine, and $20 \mu \mathrm{M}$ 4 uridine (Merck, F0503, U3750). Cortical neurons were seeded onto pre-coated wells with poly-L-lysine 5 (Merck, 15140) and laminin (invivogen, 23017-015) and hippocampal neurons were seed into $\mu$-Slide 8 well (ibidi, 80826) pre-coated with poly-D-lysine (Merck, P7886). Neurons were incubated at $37^{\circ} \mathrm{C}$ for 7 days prior to assaying with medium change every second day.

8

9

\section{Survival assays}

WT and SorCS2 ${ }^{-/-}$primary cortical neurons were plated into 12-well plates and 96-well black plate with clear bottom (Corning Incorporated, Costar, 3603). On day in vitro 7 (DIV7), neurons were incubated with $50 \mu \mathrm{M}$ CQ diphosphate (Merck, C6628) dissolved in water for $24 \mathrm{~h}$. On the next day, neurons were harvested for immunoblotting or incubated with calcein-AM and ethidium homodimer-1 (LIVE/DEAD ${ }^{\mathrm{TM}}$ Viability/Cytotoxicity Kit, Thermofisher, L3224), following the manufacturer's instructions. Fluorescence intensity was read using CLARIOstar plus plate reader (BMG labtech) with appropriate filters.

\section{Immunofluorescence}

Cultured primary hippocampal neurons plated onto $\mu$-Slide 8 well (ibidi, 80826) were fixed in 4\% paraformaldehyde, 4\% sucrose (Merck, S0389) in D-PBS for $15 \mathrm{~min}$ and permeabilized with $0.05 \%$ saponin (Merck, 47036) in D-PBS supplemented with 1\% bovine serum albumin (BSA, Merck, 05470). Primary antibodies diluted in blocking buffer were incubated with the cells at RT for $1 \mathrm{~h}$, followed by a three times 5 min washing step with blocking buffer. Alexa-conjugated secondary antibodies were sequentially incubated for $1 \mathrm{~h}$ in the same buffer, protected from light. For mounting, ibidi Mounting Medium with DAPI (ibidi, 50011) were added to the cells in the $\mu$-Slide 8 well. 


\section{Confocal Microscopy}

The immunostained samples were analyzed on a Zeiss confocal LSM 710 microscope using $63 \mathrm{x} / 1.2 \mathrm{~W}$ Korr (water immersion correction ring) objectives. Appropriate filters were used upon excitation of the different fluorophores to match their maximum fluorescence emission. Processing of the acquired images was performed in ImageJ. All images compared were subjected to similar brightness and contrast adjustments.

\section{Live cell microscopy}

For the live cell assays, WT and SorCS2 $2^{-/}$primary hippocampal neurons were plated in $\mu$-Slide 8 well and incubated as described before. On DIV6, neurons were incubated with either vehicle or $14 \mu \mathrm{g} / \mathrm{ml}$ homemade monomeric $\alpha$-synuclein for $24 \mathrm{~h}$. On DIV7, neurons were incubated with prewarmed media containing $1 \mu \mathrm{M}$ LysoSensor Green DND-189 (Thermofisher, L7535) and $0.125 \mu \mathrm{g} / \mathrm{ml}$ Hoechst 33342 (Thermofisher, H3570) for 15 min at $37^{\circ} \mathrm{C}$. Bafilomycin A1 (BafA1) was used prior to LysoSensor Green DND-189 incubation at $100 \mathrm{nM}$ for $45 \mathrm{~min}$ as a control for acidification. Cells were washed twice with D-PBS and kept in FluoroBrite DMEM media (Gibco, A1896701) supplemented with 1\% GlutaMAX for imaging. Method described before (Toth, Nielsen et al. 2019).

For the Cathepsin B live activity assay, Magic Red ${ }^{\circledR}$ Cathepsin B substrate (ImmunoChemistry Technologies, 937) was added to the neurons following manufacturer's instructions and incubated for 30, 60 and 180 min prior to imaging. At the end of the time points neurons were washed twice in D-PBS and incubated with FluoroBrite DMEM media supplemented with $1 \%$ GlutaMAX and $0.125 \mu \mathrm{g} / \mathrm{ml}$ Hoechst 33342 (provided with the Magic Red $®$ Cathepsin B kit). Cells were then imaged in a microscope equipped with a live cell imaging chamber in humidified atmosphere with $5 \% \mathrm{CO} 2$ at $37{ }^{\circ} \mathrm{C}$. Analysis of the different parameters was performed with a high content screening fluorescence microscope (Olympus BX73 microscope) fitted with the correct filter set as described below. 


\section{High content screening analysis}

Following immunocytochemistry, LysoSensor dye and Magic Red Cathepsin B activity substrate uptake, images for high content screening were obtained with the Olympus automated $\mathrm{Scan}^{\wedge} \mathrm{R}$ high content imaging station based on an Olympus BX73 microscope, with a 40×/0.9 NA air objective or 60x/0.9 NA air objective, triple-band emission filter for DAPI, FITC and Cy3, and a Hamamatsu camera (C8484$05 \mathrm{G})$. Image analysis was performed using scanR image and data analysis software for Life Science (Münster, Germany). Briefly, single-layer images were background-corrected and edge-detection algorithm was applied to segment subcellular structures based on detection of gradient intensities of the chosen color channel. The software segmented subcellular structures independently if a closed connecting line (edge) could be drawn around them and their area was larger than $0.05 \mu \mathrm{m} 2$ independently of their shape. Images with artefacts or out of focus were manually excluded. The total number of vesicles was normalized to the number of nuclei before making comparison among the adjacent groups. Number and mean fluorescent intensity of vesicles from 100 to 500 cells for each group were analyzed (Toth, Nielsen et al. 2019).

\section{Protein biochemistry and immunoblotting}

Cells were lysed and scraped in homemade Radioimmunoprecipitation assay buffer (RIPA) ((50 mM Tris pH 7.4, $150 \mathrm{mM} \mathrm{NaCl}, 1$ \% Triton X-100 (Merck, T9284), 2 mM EDTA, 0.5 \% Sodiumdeoxycholate (Merck, D6750), $0.1 \%$ sodium dodecyl sulfate (SDS) (Merck, cat. no. L6026)) supplemented with 1x cOmplete ${ }^{\mathrm{TM}}$ Protease Inhibitor Cocktail (Merck). Homogenates were centrifuged at top speed for $5 \mathrm{~min}$ at $4^{\circ} \mathrm{C}$ and supernatant was processed for protein dosage (BCA, Pierce). Samples diluted to equal concentration were prepared with NuPAGE LDS sample buffer and $0.02 \mathrm{M}$ dithiothreitol (DTT), heated for $10 \mathrm{~min}$ at $95^{\circ} \mathrm{C}$ and loaded into NuPAGE 4-12\% Bis-Tris gels; separation was carried out using MES running buffer (Thermofisher). Protein transfer was performed to nitrocellulose membranes using iBlot Transfer Stack (Thermo Fisher, IB301032 and IB301031) according to manufacturer's protocol. Membranes were blocked for $1 \mathrm{~h}$ at room temperature with blocking buffer (0.01 M Tris-Base, $0.15 \mathrm{M} \mathrm{NaCl}, 0.05 \%$ Tween-20, $5 \%$ skimmed milk powder and $0.002 \%$ azide, Ampliqon, AMPQ52300) and subsequently incubated with primary antibodies diluted in the same buffer 
overnight at $4^{\circ} \mathrm{C}$. HRP-conjugated secondary antibodies were incubated for $1 \mathrm{~h}$ at room temperature and membrane development was performed using Enhanced Chemiluminescence (ECL) Western Blotting substrate (GE healthcare, RPN2106) or ECL Prime Western Blotting substrate (GE healthcare, RPN2236). Chemiluminescent signal was imaged with Fujifilm Las3000 imaging apparatus and analyzed using Fujifilm MultiGauge software.

\section{Cathepsin B activity assays kits (Fluorometric)}

Cathepsin B activity was assessed in mouse primary neuronal samples and mouse brain hippocampus using Fluorometric Cathepsin B activity assay kit (abcam, 65300) following the manufacturer's protocol. Fluorescence intensity was read using CLARIOstar plus plate reader (BMG labtech).

\section{Lipidomics}

1 year-old WT and SorCS2 $2^{-/}$mice were euthanized by cervical dislocation. Cortex was dissected and snap frozen in liquid nitrogen and stored at $-80^{\circ} \mathrm{C}$. The lipidomics analysis was performed by the Lipidomics Core Facility at the Danish Cancer Society Research Center. Tissue was mixed with chloroform:methanol 30 10:1 (v/v) and 10x internal lipid standards containing known concentrations of various lipids followed by shaking and centrifugation. The lower phase contains the nonpolar lipids (cholesterol (Chol), cholesteryl ester (CE), ceramide (Cer), HexoseCeramide (HexCer), sphingomyelin (SM), diacylglycerol (DAG), triacylglycerol (TAG), lysophosphatidylethanolamine (LPE), lysophosphatidylcholine (LPC), phosphatidylglycerol (PG), phosphatidylethanolamine (PE), phosphatidylcholine (PC). Chloroform:methanol 2:1 (v/v) was added to the upper phase to isolate polar lipids followed by shaking and centrifugation. The lower phase contains the polar lipids (diHexoseCeramide (diHexCer), lysophosphatidic acid (LPA), lysophosphatidylinositol (LPI), lysophosphatidylserine (LPS), phosphatidic acid (PA), phosphatidylinositol (PI), phosphatidylserine (PS). The lipids were dried in a vacuum centrifuge, dissolved in chloroform:methanol 1:2 (v/v) and transferred to a 96-well plate. The samples were analyzed using a robotic nanoelectrospray ion source coupled to the MS/MS on Q Exactive Hybrid Quadrupole-Orbitrap Mass spectrometer. Lipids were identified based on the unique mass-to-charge ratio $(\mathrm{m} / \mathrm{z})$ of the intact precursor ion and the subsequent 
1 MS/MS spectra. Quantification was performed by comparing the peak intensity with the peak intensity

2 of the internal standard lipid with a known quantity.

3

\section{$4 \quad$ Statistical analysis}

5 Statistical analysis was performed using Prism software (Graphpad). All data are given as mean \pm s.e.m.

\section{Acknowledgements}

We acknowledge the invaluable technical help provided by Mette Singers, Mathias Ollendorff and the AU Health Bioimaging core facility (Department of Biomedicine, Aarhus University). We are grateful to Prof. Poul Henning Jensen (Department of Biomedicine, Aarhus University) for kindly providing mouse $\alpha$-syn protein and to Mesut Bilgin (Lipidomics Core Facility at the Danish Cancer Society Research Center) for Lipidomics sample processing. Sérgio Almeida is funded by a PhD fellowship from the PhD School at the Health Faculty, Aarhus University.

\section{Conflicts of Interest}

All authors declare no relevant conflicts of interest. 


\section{Author contributions}

2 Sérgio Almeida, André Miranda and Tiago Gil Oliveira developed the concept and designed the study.

3 Sérgio Almeida and Andrea Tóth performed experiments. Sérgio Almeida and André Miranda analyzed

4 the data. Sérgio Almeida drafted the manuscript. Morten Nielsen provided resources. Sérgio Almeida

5 and André Miranda wrote jointly the final version of the manuscript. All authors critically revised the

6 manuscript and approved the final version.

\section{7}

8

9 
A
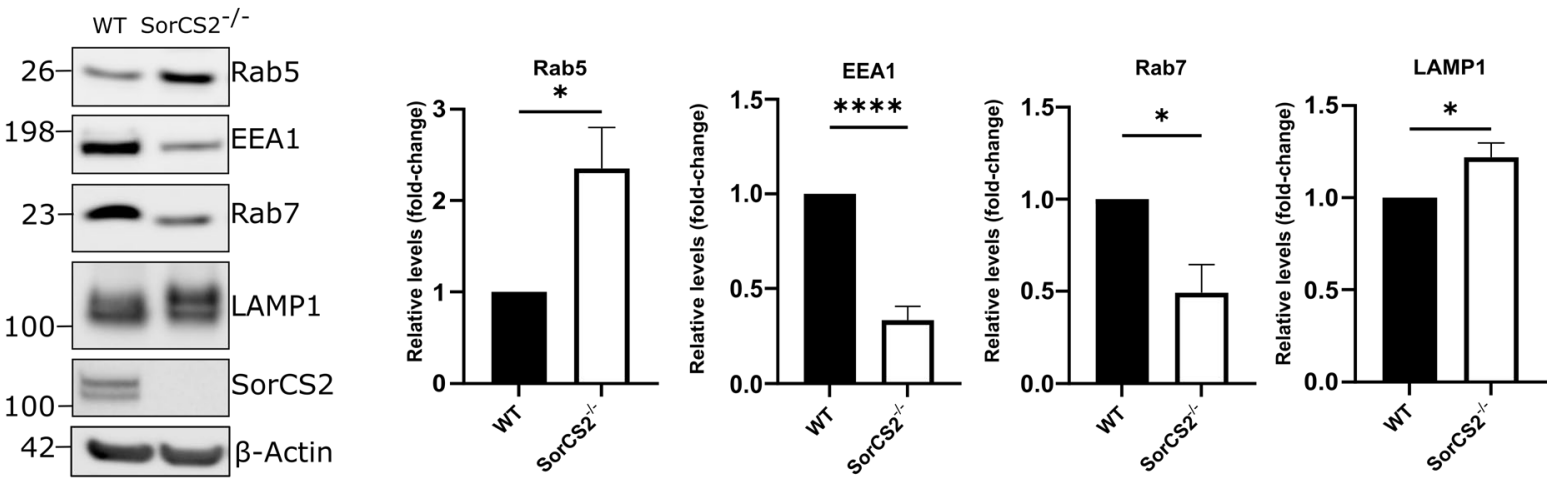

B
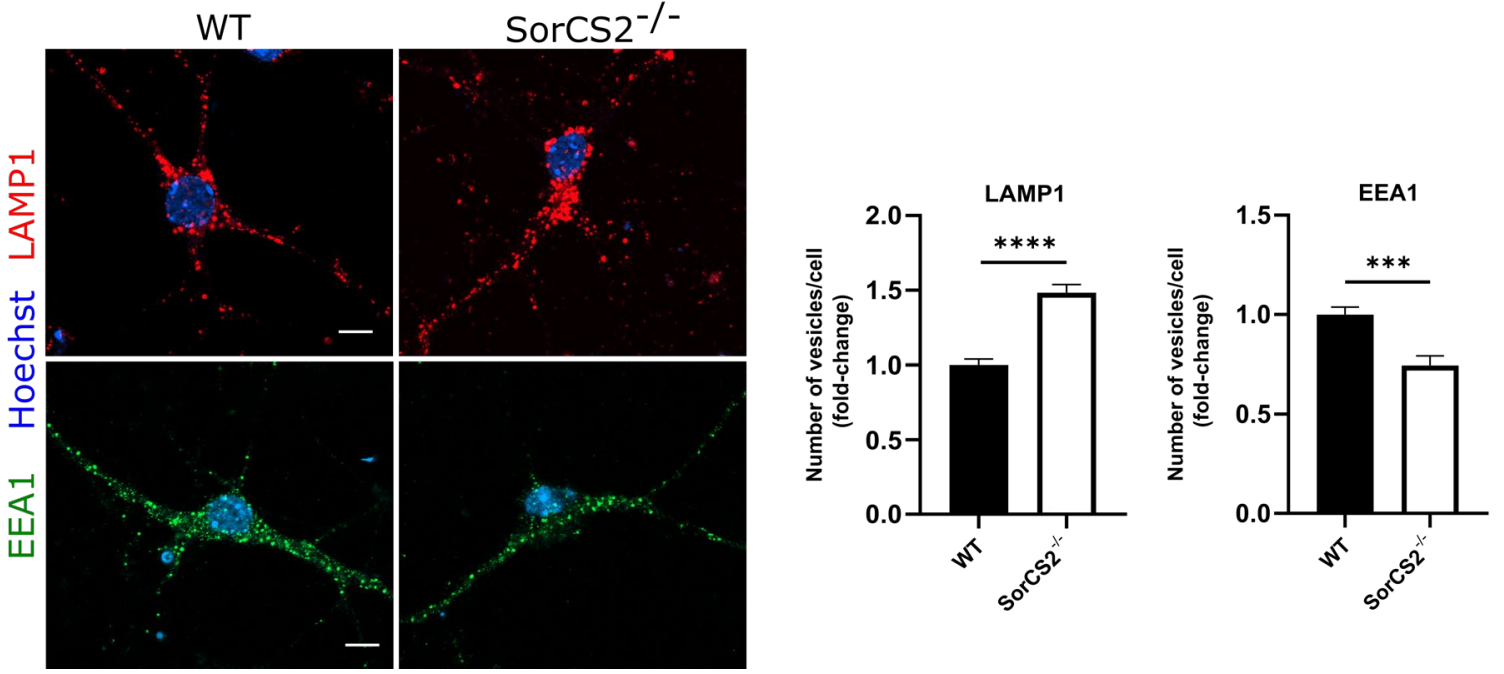

Figure 1. Absence of SorCS2 causes changes in different endo-lysosomal compartments. A. Western blot analysis of endo-lysosomal pathway associated proteins from WT and SorCS2 ${ }^{-/}$primary neurons. $\beta$-actin served as loading control. Bar graphs denote average protein levels normalized to WT (mean $\pm \mathrm{SEM}$ ). $N=6$ independent neuronal preparations per genotype. ${ }^{*} \mathrm{p}<0.05,{ }^{* *} \mathrm{p}<0.01$ (unpaired t test). B. Representative confocal images of LAMP1 (red) and EEA1 (green) immunostaining in WT (left) and SorCS2 ${ }^{-/}$(right) mouse hippocampal neurons (single confocal z planes). Cells are counterstained with Hoechst. Scale bar, $10 \mu \mathrm{m}$. Bar graphs show scanR analysis of average LAMP1 and EEA1 vesicle numbers per neuron normalized to WT (mean \pm SEM). $N=454$ and $N=280$ cells for LAMP1 staining of WT and SorCS2 $2^{-/}$respectively and $N=216$ and $N=160$ cells for EEA1 staining of WT and SorCS2 ${ }^{-/}$respectively, of three independent experiments. ${ }^{* * * *}<0.0001$ (unpaired $t$ test). 
A

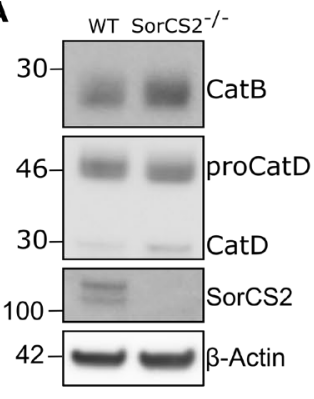

C

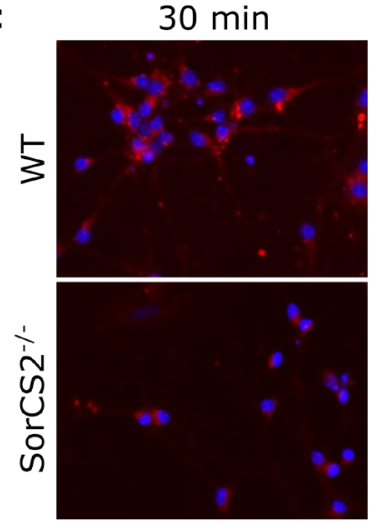

D

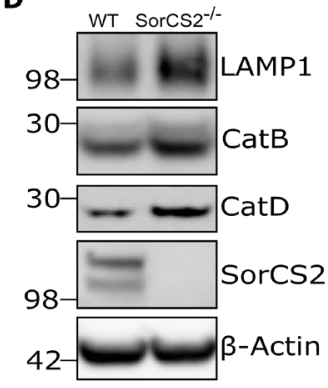

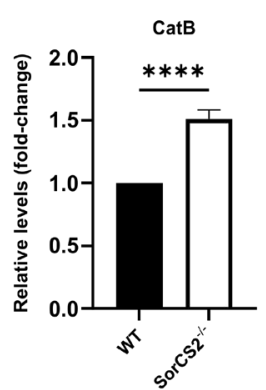
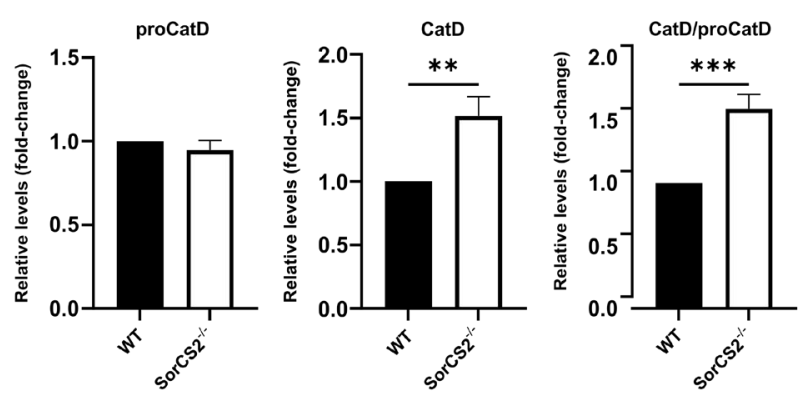

B

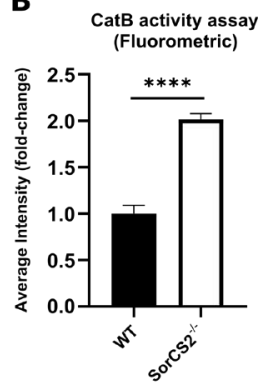

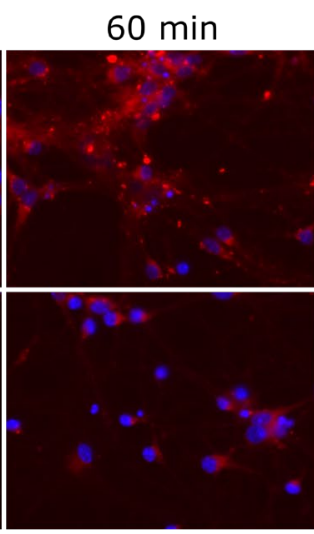
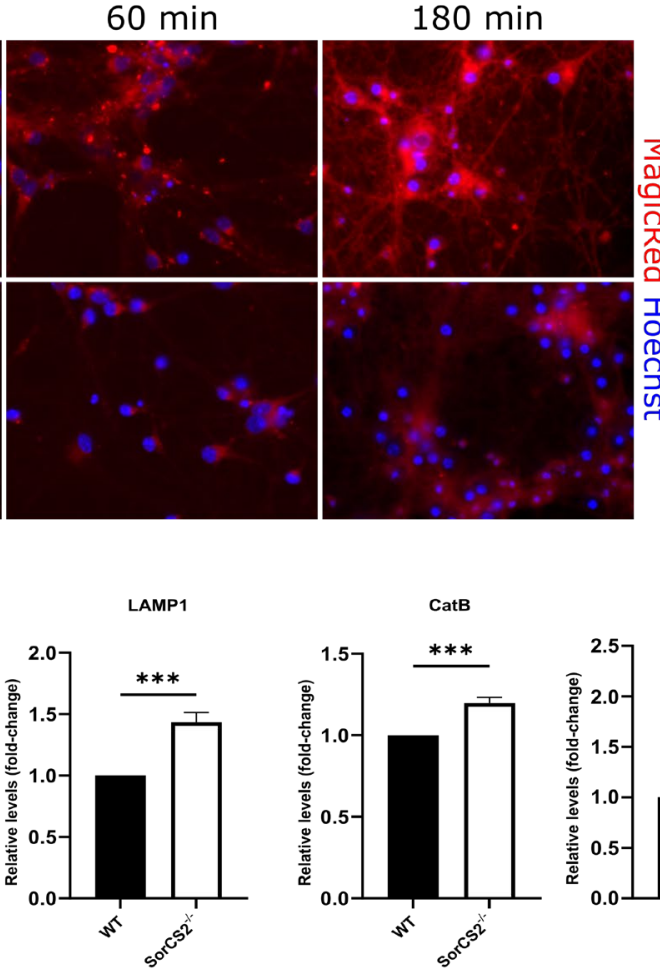
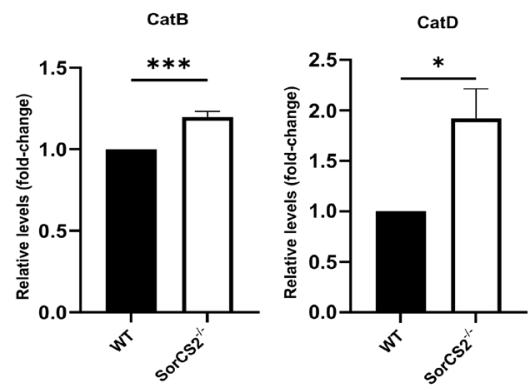

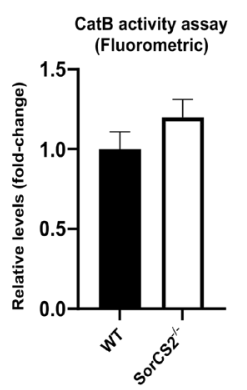

2 Figure 2 - Cathepsin maturation and activity is altered in mouse SorCS2 ${ }^{-/}$neurons and cortex. A. Western blot analysis of lysosome related proteins LAMP1 and mature Cathepsin B and D from WT and SorCS2 ${ }^{-/-}$primary neurons. $\beta$-actin served as loading control. Bar graphs denote average protein levels normalized to WT (mean $\pm \mathrm{SEM}$ ). $N=6$ independent neuronal preparations per genotype. ${ }^{*} \mathrm{p}<0.05, *^{*} \mathrm{p}<0.01$ (unpaired t test). B. Bar graph shows average fluorescent intensity resulting from abcam's Cathepsin B activity assay kit (fluorometric) from WT and SorCS2 ${ }^{-/}$primary cortical neurons, normalized to WT (mean \pm SEM). $N=4$ independent neuronal preparations per genotype. $* * * * p<0.0001$ (unpaired $t$ test). C. C. Live high content screening microscopy representative pictures of WT (top) and SorCS2 ${ }^{-/}$(bottom) primary hippocampal neurons incubated with Magic Red ${ }^{\mathrm{TM}}$ Cathepsin B substrate for the designated time points (30,60 and $\left.180 \mathrm{~min}\right)$. Cells are counterstained with Hoechst. Graph denotes average neuron fluorescent intensity for both genotypes at specified time points (mean $\pm \mathrm{SEM}$ ). $N=500$ and $N=613$ cells at $30 \mathrm{~min}, N=569$ and $N=515$ cells at $60 \mathrm{~min}, N=242$ and $N=502$ cells at $180 \mathrm{~min}$ for WT and SorCS2 ${ }^{-/}$respectively of three independent experiments. ${ }^{* * * *} \mathrm{p}<0.0001$ (two-way ANOVA with Tukey's multiple- 
1 comparisons test). D. Western blot analysis of lysosome related proteins LAMP1 and mature Cathepsin B and D from WT

2 and SorCS2 ${ }^{-/}$adult mouse cortex. $\beta$-actin served as loading control. Bar graphs denotes average protein levels normalized to

3 WT (mean \pm SEM). $N=5$ mice per genotype. ${ }^{*} \mathrm{p}<0.05,{ }^{*} \mathrm{p}<0.01$ (unpaired $\mathrm{t}$ test). E. Bar graph shows average fluorescent

4 intensity resulting from abcam's Cathepsin B activity assay kit (fluorometric) from 1-year-old WT and SorCS2 ${ }^{-/}$mouse 5 cortex, normalized to WT (mean \pm SEM). $N=10$ and 9, WT and SorCS2 $2^{-/}$mice respectively.

6

7

8

9

10

11

12

13

14

15

16

17

18

19

20

21

22

23

24

25

26

27 
A

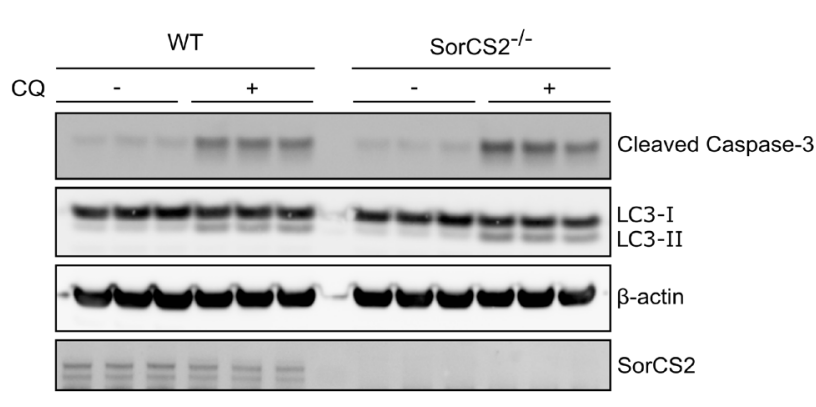

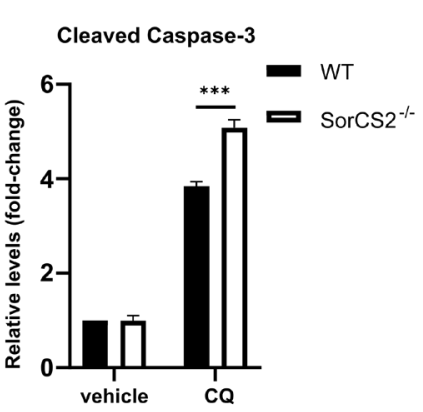

B

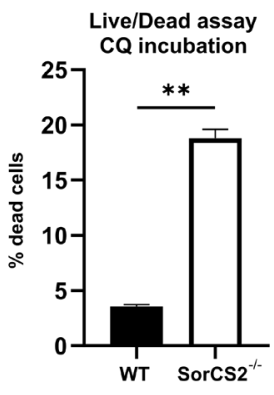

$c$

WT

SorCS2-/-

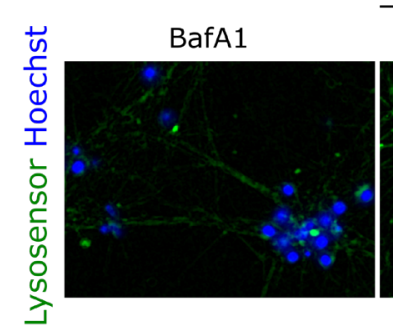

D

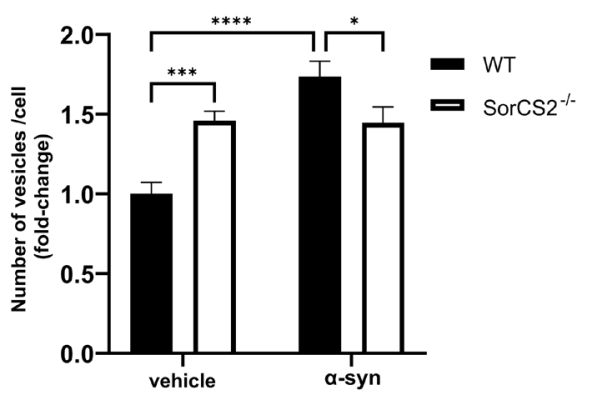

$\mathbf{E}$

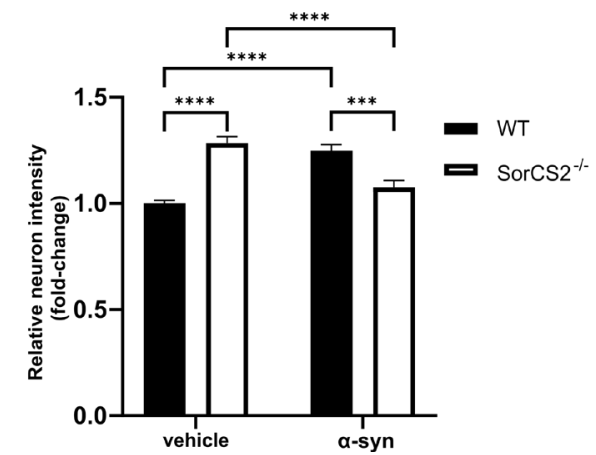

Figure 3 - SorCS2 ${ }^{-/-}$primary neurons are susceptible to lysosomal stress. A. Western blot analysis of cleaved caspase-3 levels in WT and SorCS2 $2^{-/-}$primary cortical neurons treated with vehicle or CQ at $50 \mu \mathrm{M}$ for $24 \mathrm{~h}$. LC3 serves as lysosomal impairment control and $\beta$-actin as loading control. Bar graphs denotes average protein levels normalized to WT (mean \pm SEM). $N=3$ independent neuronal cultures. ***p<0.001 (two-way ANOVA with Tukey's multiple-comparisons test). B. Bar graph shows percentage of dead WT and SorCS2 $2^{-/-}$primary cortical neurons treated with vehicle or CQ at $50 \mu \mathrm{M}$ for $24 \mathrm{~h}$ (mean $\pm \mathrm{SEM}$ ). $N=2$ independent neuronal cultures. $* * \mathrm{p}<0.01$ (unpaired t test). C. Live high content screening microscopy representative pictures of WT and SorCS2 ${ }^{-/-}$primary hippocampal neurons incubated with Lysosensor ${ }^{\mathrm{TM}}$ Green DND-189 and pre-incubated with either BafAl for at $100 \mathrm{nM}$ for $45 \mathrm{~min}$, vehicle and monomeric $\alpha$-syn for $24 \mathrm{~h}$ at $14 \mu \mathrm{g} / \mathrm{ml}$. Cells are counterstained with Hoechst. D and E. scanR analysis from images in C. D. Bar graph denotes average number of vesicles per neuron for both genotypes when treated with either vehicle or $\alpha \alpha$-syn, normalized to the WT (mean \pm SEM). $N=150$ and $N=289$ cells for vehicle treated and $N=239$ and $N=133$ cells for $\alpha$-syn treated WT and SorCS2 $2^{-/-}$respectively of three independent experiments. ${ }^{*} \mathrm{p}<0.05, * * * \mathrm{p}<0.001, * * * * \mathrm{p}<0.0001$ (two-way ANOVA with Tukey’s multiple-comparisons test). E. Graph denotes average vesicle fluorescent intensity for both genotypes when treated with either vehicle or $\alpha$-syn, normalized to the WT (mean $\pm \mathrm{SEM}$ ). $N=150$ and $N=289$ cells for vehicle treated and $N=239$ and $N=133$ cells for $\alpha$-syn treated 
bioRxiv preprint doi: https://doi.org/10.1101/2021.04.08.439000; this version posted April 10, 2021. The copyright holder for this preprint (which was not certified by peer review) is the author/funder, who has granted bioRxiv a license to display the preprint in perpetuity. It is made available under aCC-BY-NC-ND 4.0 International license.

$1 \mathrm{WT}$ and $\mathrm{SorCS}_{2}{ }^{-/}$respectively of three independent experiments. ${ }^{* * * *} \mathrm{p}<0.0001$ (two-way ANOVA with Tukey's multiple2 comparisons test).

3

4

5

6

7

8

9

10

11

12

13

14

15

16

17

18

19

20

21 
bioRxiv preprint doi: https://doi.org/10.1101/2021.04.08.439000; this version posted April 10, 2021. The copyright holder for this preprint (which was not certified by peer review) is the author/funder, who has granted bioRxiv a license to display the preprint in perpetuity. It is made available under aCC-BY-NC-ND 4.0 International license.

1

2

3

4

5

6

7

8

9

10

11

12

13

14

15

16

17

18

19
A

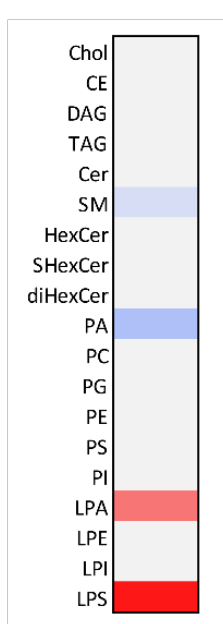

\begin{tabular}{rcccccc} 
& \multicolumn{7}{c}{ Average mol\% \pm SEM } \\
\cline { 2 - 7 } Chol & 45.440 & \pm & 0.448 & 46.358 & \pm & 0.649 \\
CE & 0.008 & \pm & 0.004 & 0.011 & \pm & 0.005 \\
DAG & 0.346 & \pm & 0.073 & 0.192 & \pm & 0.015 \\
TAG & 0.153 & \pm & 0.015 & 0.148 & \pm & 0.028 \\
Cer & 0.538 & \pm & 0.035 & 0.507 & \pm & 0.017 \\
SM & 1.544 & \pm & 0.033 & 1.398 & \pm & 0.045 \\
HexCer & 1.866 & \pm & 0.082 & 1.719 & \pm & 0.095 \\
SHexCer & 0.447 & \pm & 0.051 & 0.424 & \pm & 0.032 \\
diHexCer & 0.530 & \pm & 0.026 & 0.472 & \pm & 0.025 \\
PA & 0.238 & \pm & 0.016 & 0.186 & \pm & 0.014 \\
PC & 35.102 & \pm & 0.617 & 35.099 & \pm & 0.431 \\
PG & 0.116 & \pm & 0.006 & 0.102 & \pm & 0.011 \\
PE & 7.254 & \pm & 0.539 & 6.988 & \pm & 0.588 \\
PS & 3.603 & \pm & 0.133 & 3.475 & \pm & 0.182 \\
PI & 1.769 & \pm & 0.083 & 1.679 & \pm & 0.126 \\
LPA & 0.026 & \pm & 0.003 & 0.038 & \pm & 0.002 \\
LPE & 0.943 & \pm & 0.048 & 1.080 & \pm & 0.070 \\
LPI & 0.033 & \pm & 0.005 & 0.041 & \pm & 0.006 \\
LPS & 0.045 & \pm & 0.006 & 0.084 & \pm & 0.010
\end{tabular}

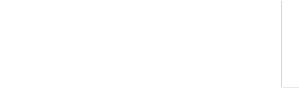

B

\begin{tabular}{|c|c|}
\hline Chol: & \\
\hline CE 16:1 & \\
\hline DAG $32: 0$ & \\
\hline DAG $34: 2$ & \\
\hline DAG $34: 1$ & \\
\hline DAG $34: 0$ & \\
\hline DAG $36: 4$ & \\
\hline DAG $36: 2$ & \\
\hline DAG $38: 6$ & \\
\hline DAG $38: 4$ & \\
\hline DAG $38: 2$ & \\
\hline DAG $40: 6$ & \\
\hline DAG $40: 4$ & \\
\hline TAG 48:0 & \\
\hline TAG 50:1 & \\
\hline TAG 50:0 & \\
\hline TAG 52:2 & \\
\hline TAG 52:1 & \\
\hline Cer $34: 1 ; 2$ & \\
\hline Cer $34: 0 ; 2$ & \\
\hline Cer $36: 2 ; 2$ & \\
\hline Cer $36: 1 ; 2$ & \\
\hline Cer $38: 1 ; 2$ & \\
\hline Cer 40:2;2 & \\
\hline Cer $40: 1 ; 2$ & \\
\hline Cer $42: 2 ; 2$ & \\
\hline Cer $42: 1 ; 2$ & \\
\hline SM $34: 1 ; 2$ & \\
\hline SM $36: 2 ; 2$ & \\
\hline SM $36: 1 ; 2$ & \\
\hline SM $38: 1 ; 2$ & \\
\hline SM $40: 1 ; 2$ & \\
\hline SM $42: 2 ; 2$ & \\
\hline$x$ Cer 36:1;2 & \\
\hline$x$ Cer 38:1;2 & \\
\hline$x$ Cer $40: 2 ; 2$ & \\
\hline$x \operatorname{Cer} 40: 1 ; 2$ & \\
\hline
\end{tabular}

$p<0.05$

$p<0.01$

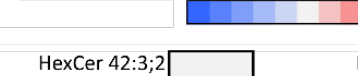

\begin{tabular}{|c|c|}
\hline PC 40:8 & PS 38:5 \\
\hline PC 40:7 & PS $38: 4$ \\
\hline PC 40:6 & PS $38: 2$ \\
\hline PC 40:5 & PS $38: 1$ \\
\hline PC 40:4 & PS 40:7 \\
\hline PC 40:2 & PS 40:6 \\
\hline PC 40:1 & PS $40: 4$ \\
\hline PC 42:9 & PS $40: 2$ \\
\hline PC 42:7 & PS 40:1 \\
\hline PC 42:5 & PS 42:10 \\
\hline PC 42:2 & PS 42:7 \\
\hline PC $44: 10$ & PS $44: 12$ \\
\hline PG 34:1 & PS $44: 10$ \\
\hline PG 34:0 & PI $34: 0$ \\
\hline PG 36:4 & PI 36:4 \\
\hline PG 36:2 & PI 36:1 \\
\hline PG 36:1 & PI 38:6 \\
\hline PG 38:4 & PI 38:5 \\
\hline PG 42:10 & PI 38:4 \\
\hline PG 44:12 & PI 40:8 \\
\hline PE $34: 2$ & PI 40:7 \\
\hline PE 34:1 & PI 40:6 \\
\hline PE 34:0 & LPA 16:0 \\
\hline PE 36:4 & LPA $18: 1$ \\
\hline PE 36:2 & LPA $18: 0$ \\
\hline PE 36:1 & LPE $16: 1$ \\
\hline PE 38:6 & LPE 16:0 \\
\hline PE 38:5 & LPE 18:1 \\
\hline PE 38:4 & LPE $18: 0$ \\
\hline PE 38:2 & LPE 20:4 \\
\hline PE 40:7 & LPE 22:6 \\
\hline PE 40:6 & LPE 22:5 \\
\hline PS $34: 1$ & LPE 22:4 \\
\hline PS $36: 4$ & LPI 18:0 \\
\hline PS $36: 2$ & LPS $18: 1$ \\
\hline PS $36: 1$ & LPS $18: 0$ \\
\hline PS 38:6 & \\
\hline
\end{tabular}

20 Figure 4. Lipidomics analysis of WT and SorCS2 ${ }^{-/}$mouse cortex. MS/MS analysis of A. Lipid classes and B. Lipid species

21 displayed as a Heatmap from 1-year-old WT and SorCS2 ${ }^{-/}$mouse cortex. For lipid nomenclature, consult Methods section. 
bioRxiv preprint doi: https://doi.org/10.1101/2021.04.08.439000; this version posted April 10, 2021. The copyright holder for this preprint (which was not certified by peer review) is the author/funder, who has granted bioRxiv a license to display the preprint in perpetuity. It is made available under aCC-BY-NC-ND 4.0 International license.

1 Values are expressed as average mol\% of total lipid measured, normalized to WT (mean $\pm \operatorname{SEM}, N=10$ and 9, WT and SorCS2-

$2 \quad$ /- mice respectively)

3

4

5

6

7

8

9

10

11

12

13

14

15

16

17

18

19

20

21

22 


\section{References}

Aits, S., J. Kricker, B. Liu, A. M. Ellegaard, S. Hämälistö, S. Tvingsholm, E. Corcelle-Termeau, S. Høgh, T. Farkas, A. Holm Jonassen, I. Gromova, M. Mortensen and M. Jäättelä (2015). "Sensitive detection of lysosomal membrane permeabilization by lysosomal galectin puncta assay." Autophagy 11(8): 1408-1424.

Alemany, S., M. Ribasés, N. Vilor-Tejedor, M. Bustamante, C. Sánchez-Mora, R. Bosch, V. Richarte, B. Cormand, M. Casas, J. A. Ramos-Quiroga and J. Sunyer (2015). "New suggestive genetic loci and biological pathways for attention function in adult attention-deficit/hyperactivity disorder." Am J Med Genet B Neuropsychiatr Genet 168(6): 459-470.

Anastasia, A., K. Deinhardt, M. V. Chao, N. E. Will, K. Irmady, F. S. Lee, B. L. Hempstead and C. Bracken (2013). "Val66Met polymorphism of BDNF alters prodomain structure to induce neuronal growth cone retraction." Commun 4: 2490.

Andersen, O. M., J. Reiche, V. Schmidt, M. Gotthardt, R. Spoelgen, J. Behlke, C. A. von Arnim, T. Breiderhoff, P. Jansen, X. Wu, K. R. Bales, R. Cappai, C. L. Masters, J. Gliemann, E. J. Mufson, B. T. Hyman, S. M. Paul, A. Nykjaer and T. E. Willnow (2005). "Neuronal sorting protein-related receptor sorLA/LR11 regulates processing of the amyloid precursor protein." Proc Natl Acad Sci U S A 102(38): 13461-13466.

Arighi, C. N., L. M. Hartnell, R. C. Aguilar, C. R. Haft and J. S. Bonifacino (2004). "Role of the mammalian retromer in sorting of the cation-independent mannose 6-phosphate receptor." J Cell Biol 165(1): 123-133. Backer, J. M. (2016). "The intricate regulation and complex functions of the Class III phosphoinositide 3-kinase Vps34." Biochem J 473(15): 2251-2271.

Baum, A. E., N. Akula, M. Cabanero, I. Cardona, W. Corona, B. Klemens, T. G. Schulze, S. Cichon, M. Rietschel, M. M. Nöthen, A. Georgi, J. Schumacher, M. Schwarz, R. Abou Jamra, S. Höfels, P. Propping, J. Satagopan, S. D. Detera-Wadleigh, J. Hardy, F. J. McMahon and N. G. I. B. D. Consortium (2008). "A genome-wide association study implicates diacylglycerol kinase eta (DGKH) and several other genes in the etiology of bipolar disorder." Molecular Psychiatry 13(2): 197-207.

Bissig, C. and J. Gruenberg (2013). "Lipid sorting and multivesicular endosome biogenesis." Cold Spring Harb Perspect Biol 5(10): a016816.

Braulke, T. and J. S. Bonifacino (2009). "Sorting of lysosomal proteins." Biochim Biophys Acta 1793(4): 605-614. Bulankina, A. V., A. Deggerich, D. Wenzel, K. Mutenda, J. G. Wittmann, M. G. Rudolph, K. N. Burger and S. Höning (2009). "TIP47 functions in the biogenesis of lipid droplets." J Cell Biol 185(4): 641-655. Burd, C. and P. J. Cullen (2014). "Retromer: a master conductor of endosome sorting." Cold Spring Harb Perspect Biol 6(2).

Canuel, M., A. Korkidakis, K. Konnyu and C. R. Morales (2008). "Sortilin mediates the lysosomal targeting of cathepsins D and H." Biochem Biophys Res Commun 373(2): 292-297.

Chevallier, J., Z. Chamoun, G. Jiang, G. Prestwich, N. Sakai, S. Matile, R. G. Parton and J. Gruenberg (2008). "Lysobisphosphatidic acid controls endosomal cholesterol levels." J Biol Chem 283(41): 27871-27880. Christoforou, A., K. A. McGhee, S. W. Morris, P. A. Thomson, S. Anderson, A. McLean, H. S. Torrance, S. Le Hellard, B. S. Pickard, D. StClair, W. J. Muir, D. H. Blackwood, D. J. Porteous and K. L. Evans (2011). "Convergence of linkage, association and GWAS findings for a candidate region for bipolar disorder and schizophrenia on chromosome 4p." Molecular Psychiatry 16(3): 240-242.

Cui, Y., J. M. Carosi, Z. Yang, N. Ariotti, M. C. Kerr, R. G. Parton, T. J. Sargeant and R. D. Teasdale (2019). "Retromer has a selective function in cargo sorting via endosome transport carriers." J Cell Biol 218(2): 615631.

D'Arrigo, P. and S. Servi (2010). "Synthesis of lysophospholipids." Molecules 15(3): 1354-1377. 
Dall'Armi, C., A. Hurtado-Lorenzo, H. Tian, E. Morel, A. Nezu, R. B. Chan, W. H. Yu, K. S. Robinson, O. Yeku, S. A. Small, K. Duff, M. A. Frohman, M. R. Wenk, A. Yamamoto and G. Di Paolo (2010). "The phospholipase D1 pathway modulates macroautophagy." Nat Commun 1: 142.

Deinhardt, K., T. Kim, D. S. Spellman, R. E. Mains, B. A. Eipper, T. A. Neubert, M. V. Chao and B. L. Hempstead (2011). "Neuronal growth cone retraction relies on proneurotrophin receptor signaling through Rac." Sci Signal 4(202): ra82. Freeman, D., R. Cedillos, S. Choyke, Z. Lukic, K. McGuire, S. Marvin, A. M. Burrage, S. Sudholt, A. Rana, C. O'Connor, C. M. Wiethoff and E. M. Campbell (2013). "Alpha-synuclein induces lysosomal rupture and cathepsin dependent reactive oxygen species following endocytosis." PLoS One 8(4): e62143.

Fuller, N. and R. P. Rand (2001). "The Influence of Lysolipids on the Spontaneous Curvature and Bending Elasticity of Phospholipid Membranes." Biophysical Journal 81(1): 243-254.

Gary-Bobo, M., P. Nirdé, A. Jeanjean, A. Morère and M. Garcia (2007). "Mannose 6-phosphate receptor targeting and its applications in human diseases." Current medicinal chemistry 14(28): 2945-2953.

Ghosh, P., N. M. Dahms and S. Kornfeld (2003). "Mannose 6-phosphate receptors: new twists in the tale." Nat Rev Mol Cell Biol 4(3): 202-212.

Glerup, S., U. Bolcho, S. Mølgaard, S. Bøggild, C. B. Vaegter, A. H. Smith, J. L. Nieto-Gonzalez, P. L. Ovesen, L. F. Pedersen, A. N. Fjorback, M. Kjolby, H. Login, M. M. Holm, O. M. Andersen, J. R. Nyengaard, T. E. Willnow, K. Jensen and A. Nykjaer (2016). "SorCS2 is required for BDNF-dependent plasticity in the hippocampus." Mol Psychiatry 21(12): 1740-1751.

Glerup, S., D. Olsen, C. B. Vaegter, C. Gustafsen, S. S. Sjoegaard, G. Hermey, M. Kjolby, S. Molgaard, M. Ulrichsen, S. Boggild, S. Skeldal, A. N. Fjorback, J. R. Nyengaard, J. Jacobsen, D. Bender, C. R. Bjarkam, E. S. Sorensen, E. M. Fuchtbauer, G. Eichele, P. Madsen, T. E. Willnow, C. M. Petersen and A. Nykjaer (2014). "SorCS2 regulates dopaminergic wiring and is processed into an apoptotic two-chain receptor in peripheral glia." Neuron 82(5): 1074-1087.

Glerup, S., D. Olsen, C. B. Vaegter, C. Gustafsen, S. S. Sjoegaard, G. Hermey, M. Kjolby, S. Molgaard, M. Ulrichsen, S. Boggild, S. Skeldal, A. N. Fjorback, J. R. Nyengaard, J. Jacobsen, D. Bender, C. R. Bjarkam, E. S. Sørensen, E. M. Füchtbauer, G. Eichele, P. Madsen, T. E. Willnow, C. M. Petersen and A. Nykjaer (2014). "SorCS2 regulates dopaminergic wiring and is processed into an apoptotic two-chain receptor in peripheral glia." Neuron 82(5): 1074-1087.

Harayama, T. and H. Riezman (2018). "Understanding the diversity of membrane lipid composition." Nature Reviews Molecular Cell Biology 19(5): 281-296.

Hermey, G., I. B. Riedel, W. Hampe, H. C. Schaller and I. Hermans-Borgmeyer (1999). "Identification and Characterization of SorCS, a Third Member of a Novel Receptor Family." Biochemical and Biophysical Research Communications 266(2): 347-351.

Hirst, J., D. N. Itzhak, R. Antrobus, G. H. H. Borner and M. S. Robinson (2018). "Role of the AP-5 adaptor protein complex in late endosome-to-Golgi retrieval." PLoS Biol 16(1): e2004411.

Hoffmann, A.-C., G. Minakaki, S. Menges, R. Salvi, S. Savitskiy, A. Kazman, H. Vicente Miranda, D. Mielenz, J. Klucken, J. Winkler and W. Xiang (2019). "Extracellular aggregated alpha synuclein primarily triggers lysosomal dysfunction in neural cells prevented by trehalose." Scientific Reports 9(1): 544.

Hu, F., T. Padukkavidana, C. B. Vægter, O. A. Brady, Y. Zheng, I. R. Mackenzie, H. H. Feldman, A. Nykjaer and S. M. Strittmatter (2010). "Sortilin-mediated endocytosis determines levels of the frontotemporal dementia protein, progranulin." Neuron 68(4): 654-667.

Jiang, P., M. Gan, S.-H. Yen, P. J. McLean and D. W. Dickson (2017). "Impaired endo-lysosomal membrane integrity accelerates the seeding progression of $\alpha$-synuclein aggregates." Scientific Reports 7(1): 7690. Kågedal, K., M. Zhao, I. Svensson and U. T. Brunk (2001). "Sphingosine-induced apoptosis is dependent on lysosomal proteases." Biochem J 359(Pt 2): 335-343. 
Lin, G., P. T. Lee, K. Chen, D. Mao, K. L. Tan, Z. Zuo, W. W. Lin, L. Wang and H. J. Bellen (2018). "Phospholipase PLA2G6, a Parkinsonism-Associated Gene, Affects Vps26 and Vps35, Retromer Function, and Ceramide Levels, Similar to $\alpha$-Synuclein Gain." Cell Metab 28(4): 605-618.e606.

Ma, Q., J. Yang, T. A. Milner, J. G. Vonsattel, M. E. Palko, L. Tessarollo and B. L. Hempstead (2017). "SorCS2mediated NR2A trafficking regulates motor deficits in Huntington's disease." JCI Insight 2(9).

Malik, A. R., K. Szydlowska, K. Nizinska, A. Asaro, E. A. van Vliet, O. Popp, G. Dittmar, R. Fritsche-Guenther, J. A. Kirwan, A. Nykjaer, K. Lukasiuk, E. Aronica and T. E. Willnow (2019). "SorCS2 Controls Functional Expression of Amino Acid Transporter EAAT3 and Protects Neurons from Oxidative Stress and Epilepsy-Induced Pathology." Cell Rep 26(10): 2792-2804.e2796.

Mari, M., M. V. Bujny, D. Zeuschner, W. J. Geerts, J. Griffith, C. M. Petersen, P. J. Cullen, J. Klumperman and H. J. Geuze (2008). "SNX1 defines an early endosomal recycling exit for sortilin and mannose 6-phosphate receptors." Traffic 9(3): 380-393.

Miranda, A. M., Z. M. Lasiecka, Y. Xu, J. Neufeld, S. Shahriar, S. Simoes, R. B. Chan, T. G. Oliveira, S. A. Small and G. Di Paolo (2018). "Neuronal lysosomal dysfunction releases exosomes harboring APP C-terminal fragments and unique lipid signatures." Nat Commun 9(1): 291.

Miura, E., T. Hasegawa, M. Konno, M. Suzuki, N. Sugeno, N. Fujikake, S. Geisler, M. Tabuchi, R. Oshima, A. Kikuchi, T. Baba, K. Wada, Y. Nagai, A. Takeda and M. Aoki (2014). "VPS35 dysfunction impairs lysosomal degradation of $\alpha$-synuclein and exacerbates neurotoxicity in a Drosophila model of Parkinson's disease." Neurobiol Dis 71: 1-13.

Mizushima, N., T. Yoshimori and B. Levine (2010). "Methods in mammalian autophagy research." Cell 140(3): 313-326.

$\mathrm{Ni}, \mathrm{X}$. and C. R. Morales (2006). "The lysosomal trafficking of acid sphingomyelinase is mediated by sortilin and mannose 6-phosphate receptor." Traffic 7(7): 889-902.

Nielsen, M. S., P. Madsen, E. I. Christensen, A. Nykjaer, J. Gliemann, D. Kasper, R. Pohlmann and C. M. Petersen (2001). "The sortilin cytoplasmic tail conveys Golgi-endosome transport and binds the VHS domain of the GGA2 sorting protein." Embo i 20(9): 2180-2190.

Ollila, H. M., P. Soronen, K. Silander, O. M. Palo, T. Kieseppä, M. A. Kaunisto, J. Lönnqvist, L. Peltonen, T. Partonen and T. Paunio (2009). "Findings from bipolar disorder genome-wide association studies replicate in a Finnish bipolar family-cohort." Molecular Psychiatry 14(4): 351-353.

Olsen, D., N. Wellner, M. Kaas, I. E. M. de Jong, F. Sotty, M. Didriksen, S. Glerup and A. Nykjaer (2021). "Altered dopaminergic firing pattern and novelty response underlie ADHD-like behavior of SorCS2-deficient mice." Transl Psychiatry 11(1): 74.

Philtjens, S., S. Van Mossevelde, J. van der Zee, E. Wauters, L. Dillen, M. Vandenbulcke, R. Vandenberghe, A. Ivanoiu, A. Sieben, C. Willems, L. Benussi, R. Ghidoni, G. Binetti, B. Borroni, A. Padovani, P. Pastor, M. DiezFairen, M. Aguilar, A. de Mendonca, G. Miltenberger-Miltenyi, I. Hernandez, M. Boada, A. Ruiz, B. Nacmias, S. Sorbi, M. R. Almeida, I. Santana, J. Clarimon, A. Lleo, G. B. Frisoni, R. Sanchez-Valle, A. Llado, E. Gomez-Tortosa, E. Gelpi, M. Van den Broeck, K. Peeters, P. Cras, P. P. De Deyn, S. Engelborghs, M. Cruts and C. Van Broeckhoven (2018). "Rare nonsynonymous variants in SORT1 are associated with increased risk for frontotemporal dementia." Neurobiol Aging 66: 181.e183-181.e110.

Poole, B. and S. Ohkuma (1981). "Effect of weak bases on the intralysosomal pH in mouse peritoneal macrophages." J Cell Biol 90(3): 665-669.

Rogaeva, E., Y. Meng, J. H. Lee, Y. Gu, T. Kawarai, F. Zou, T. Katayama, C. T. Baldwin, R. Cheng, H. Hasegawa, F. Chen, N. Shibata, K. L. Lunetta, R. Pardossi-Piquard, C. Bohm, Y. Wakutani, L. A. Cupples, K. T. Cuenco, R. C. Green, L. Pinessi, I. Rainero, S. Sorbi, A. Bruni, R. Duara, R. P. Friedland, R. Inzelberg, W. Hampe, H. Bujo, Y. Q. Song, O. M. Andersen, T. E. Willnow, N. Graff-Radford, R. C. Petersen, D. Dickson, S. D. Der, P. E. Fraser, G. 
Schmitt-Ulms, S. Younkin, R. Mayeux, L. A. Farrer and P. St George-Hyslop (2007). "The neuronal sortilin-related receptor SORL1 is genetically associated with Alzheimer disease." Nat Genet 39(2): 168-177.

Santa-Marinha, L., I. Castanho, R. R. Silva, F. V. Bravo, A. M. Miranda, T. Meira, R. Morais-Ribeiro, F. Marques, Y. Xu, K. Point du Jour, M. Wenk, R. B. Chan, G. Di Paolo, V. Pinto and T. G. Oliveira (2020). "Phospholipase D1

Ablation Disrupts Mouse Longitudinal Hippocampal Axis Organization and Functioning." Cell Reports 30(12): 4197-4208.e4196.

Sarkar, C., J. W. Jones, N. Hegdekar, J. A. Thayer, A. Kumar, A. I. Faden, M. A. Kane and M. M. Lipinski (2020). "PLA2G4A/cPLA2-mediated lysosomal membrane damage leads to inhibition of autophagy and neurodegeneration after brain trauma." Autophagy 16(3): 466-485.

Seaman, M. N. (2004). "Cargo-selective endosomal sorting for retrieval to the Golgi requires retromer." J Cell Biol 165(1): 111-122.

Seaman, M. N. (2007). "Identification of a novel conserved sorting motif required for retromer-mediated endosome-to-TGN retrieval." J Cell Sci 120(Pt 14): 2378-2389.

Seaman, M. N. J. (2018). "Retromer and the cation-independent mannose 6-phosphate receptor-Time for a trial separation?" Traffic 19(2): 150-152.

Seglen, P. O., B. Grinde and A. E. Solheim (1979). "Inhibition of the lysosomal pathway of protein degradation in isolated rat hepatocytes by ammonia, methylamine, chloroquine and leupeptin." Eur J Biochem 95(2): 215-225. Toth, A. E., S. S. E. Nielsen, W. Tomaka, N. J. Abbott and M. S. Nielsen (2019). "The endo-lysosomal system of bEnd.3 and hCMEC/D3 brain endothelial cells." Fluids and Barriers of the CNS 16(1): 14.

Wang, D., C. C. Chan, S. Cherry and P. R. Hiesinger (2013). "Membrane trafficking in neuronal maintenance and degeneration." Cell Mol Life Sci 70(16): 2919-2934.

Wassmer, T., N. Attar, M. V. Bujny, J. Oakley, C. J. Traer and P. J. Cullen (2007). "A loss-of-function screen reveals SNX5 and SNX6 as potential components of the mammalian retromer." J Cell Sci 120(Pt 1): 45-54. Willnow, T. E., C. M. Petersen and A. Nykjaer (2008). "VPS10P-domain receptors - regulators of neuronal viability and function." Nature Reviews Neuroscience 9(12): 899-909.

Yang, J., Q. Ma, I. Dincheva, J. Giza, D. Jing, T. Marinic, T. A. Milner, A. Rajadhyaksha, F. S. Lee and B. L. Hempstead (2021). "SorCS2 is required for social memory and trafficking of the NMDA receptor." Molecular Psychiatry 26(3): 927-940.

Zhang, L., R. Sheng and Z. Qin (2009). "The lysosome and neurodegenerative diseases." Acta Biochimica et Biophysica Sinica 41(6): 437-445. 